\title{
José I, “EI Rey Regenerador". El discurso josefino sobre la regeneración de España
}

\author{
Antonio J. Piqueres DíEz \\ Universidad de Alicante \\ aj.piqueres@ua.es
}

Fecha de recepción: 19/11/2011

Fecha de aceptación: 10/09/2012

\section{RESUMEN}

La invasión napoleónica de España a principios de 1808 inauguró uno de los periodos más convulsos de su historia. Las abdicaciones de la familia Borbón y la entronización de José Bonaparte exacerbaron los ánimos de los españoles. En medio de este contexto de guerra, sin embargo, José I emprendió un ambicioso plan de reformas para regenerar la monarquía. La política, la economía o la educación fueron algunas de las esferas renovadas. El servicio de propaganda josefino, en gran medida controlado por Napoleón, pronto difundió una imagen legitimadora de José I como "rey regenerador". La crítica a la gestión de la casa Borbón formaba parte de la misma estrategia, pero la respuesta de la propaganda antibonapartista y, sobre todo, la desconfianza del pueblo, frustraron los planes josefinos.

Palabras clave: Regeneración, José I Bonaparte, Napoleón, España, guerra de la Independencia, propaganda.

\section{Joseph I, "The Regenerative King". The Josefino's Speech on the Regeneration of Spain}

\begin{abstract}
The Napoleonic invasion of Spain in 1808 supposed one of the most turbulent periods in its history. The abdications in the Bourbon family and Joseph Bonaparte's enthronement exacerbated the minds of Spaniards. Within this context of war, however, Joseph I undertook an ambitious reform plan to regenerate the monarchy. Politics, the economy, and the education were some of the renewed areas. Joseph's propaganda service, largely controlled by Napoleon, soon spread a legitimizing image of Joseph I as "King regenerator". Part of the same strategy consisted in criticizing the Bourbon's management; however, the response of the anti-Bonapartist propaganda and, mainly, the distrust of the people frustrated Joseph's plans.
\end{abstract}

Key words: Regeneration, Joseph I Bonaparte, Napoleon, Spain, Peninsular War, propaganda. 


\section{La regeneración de la Monarquía, una necesidad nacional}

La voz "regeneración" es uno de los conceptos con más presencia en el vocabulario político del siglo XIX español. Su versatilidad y polisemia ha facilitado la apropiación del término "por toda suerte de ideologías y movimientos políticos", en el que caben dosis diversas de nacionalismo herido, inconformismo y arbitrismo, y que puede ser utilizado como sinónimo de revolución y como alternativa no revolucionaria. La voz regeneración no surge del devenir específico de la España de la guerra de la Independencia, sino en la Revolución Francesa de 1789. Como recoge Juan Francisco Fuentes en el Diccionario político y social del siglo XIX español, "la voz régénération servirá en la Francia revolucionaria para expresar el deseo de revitalizar una sociedad y un Estado sumidos en un grave proceso degenerativo y de llevar a cabo el ideal ilustrado del hombre nuevo". A partir de 1808, sin embargo, este término fue muy utilizado en España por Napoleón y la propaganda josefina para defender su proyecto dinástico. Aunque en menor medida, los patriotas también recurrieron entonces al concepto, pero fue para estigmatizarlo ${ }^{1}$.

El 25 de mayo de 1808, cuando Napoleón informó a los españoles de la convocatoria de una asamblea general de las diputaciones de las provincias y de las ciudades para elaborar una Constitución que conciliase la autoridad del futuro rey y las libertades del pueblo, no dudó en aclarar:

Españoles: después de una larga agonía, vuestra nación iba a perecer. He visto vuestros males, y voy a remediarlos. Vuestra grandeza y vuestro poder hacen parte del mío. [...] Vuestra monarquía es vieja: mi misión se dirige a renovarla; mejoraré vuestras instituciones, y os haré gozar de los beneficios de una reforma, sin que experimentéis quebrantos, desórdenes ni convulsiones. [...] Españoles: acordaos de lo que han sido vuestros padres, y mirad a lo que habéis llegado. No es vuestra la culpa, sino del mal gobierno que os regía. Tened suma esperanza y confianza en las circunstancias actuales; pues Yo quiero que mi memoria llegue hasta vuestros últimos nietos, y que exclamen: Es el regenerador de nuestra patria ${ }^{2}$.

El 20 de abril, a la llegada del séquito de Fernando VII a Bayona, el emperador ya le había declarado al infante don Carlos su determinación de no tolerar que la dinastía de los Borbones ocupase más tiempo el trono de España. El control del reino se había convertido en una prioridad para Napoleón y por ello después de su invasión sentó a su hermano José en el trono. La salida de la casa Borbón y la entronización de un rey extranjero rompían con la tradición monárquica española, aunque no era la primera vez. El emperador, no obstante, aprovechó su dilatada experiencia en materia de propaganda para legitimar el cambio dinástico. Los argumentos esgrimidos fueron tres: la convocatoria de la Asamblea y la Constitución de Bayona, la renuncia voluntaria de la vieja dinastía, y el origen providencial del poder de los Bonaparte. En búsqueda de reconocimiento nacional el emperador quiso implicar al Consejo de Castilla en la

1 Fernández Sebastián, Javier, Fuentes Aragonés, Juan Francisco (dirs.): Diccionario politico y social del siglo XIX español, Madrid, Alianza, 2002, pp. 603-608.

2 Gazeta de Madrid, 3-6-1808. 
entronización de José, y aunque este órgano nunca solicitó su designación ${ }^{3}$, el decreto de coronación estableció que la iniciativa había partido del Consejo de Castilla, de la Junta de Estado y de la villa de Madrid ${ }^{4}$. Para enmascarar su implicación y aparecer ante los españoles como un mero espectador, Napoleón les hizo creer que los diputados de Bayona elegirían a su futuro rey. Sin embargo, la secuencia cronológica de los acontecimientos ilustra la escasa función legitimadora dada al órgano. La junta inaugural se celebró el 15 de junio de 1808, pero para entonces los vocales solo pudieron ratificar la coronación, pues el día 6 Napoleón ya había comunicado al Consejo de Castilla que nombraría "Rey de España y de las Indias a su augusto hermano Josef Napoleón, actualmente Rey de Nápoles y Sicilia"s. Las abdicaciones de Fernando VII y Carlos IV también fueron manipuladas. Los medios napoleónicos siempre hablaron de cesión voluntaria, pero las renuncias fueron obligadas, algo sabido por casi todos en la época ${ }^{6}$. Una vez en Bayona, José siguió el ejemplo de su hermano y defendió sus derechos al trono haciendo uso de iguales argumentos ${ }^{7}$. El fervor religioso del pueblo también fue aprovechado por el emperador para justificar su presencia y la de José en España, y desde Bayona apeló a la Providencia como origen de su poder para dirigir el futuro de la monarquía ${ }^{8}$. La primera vez que José se refirió a la Providencia como fuente de poder fue el 10 de junio de 1808, en el decreto de aceptación del trono 9 . Pero en adelante las alusiones a ello fueron habituales, sobre todo entre los eclesiásticos. Félix Amat, arzobispo de Palmira y abad de San Ildefonso, dio cuenta de esta "filiación" pronto: "Dios ha dado a Napoleón el talento y fuerza para ser árbitro de Europa. Dios ha querido poner en sus manos los destinos de la España [...]"10. En 1809, Gerardo Vázquez, obispo de Salamanca, redactó una pastoral a favor de José en la que defendió el origen divino de su poder. El obispo argumentaba que Dios era quien quitaba y daba los imperios y advertía que lo más sensato y católico era que el pueblo se sometiera a los designios de José ${ }^{11}$.

Pasado este "trámite", Napoleón trató de convencer a los españoles de sus buenos propósitos. El emperador pretendió ilusionar al pueblo con su proyecto político, aunque el entusiasmo fernandino de la mayoría no facilitó la misión. La regeneración del reino se convierte entonces en una de las señas de identidad de los Bonaparte, según ellos, los únicos capaces de regir el rumbo de la monarquía. El emperador, deseoso de

3 Napoleón a Murat, 23-5-1808 (cit. por FernÁndez SARAsola, Ignacio: La Constitución de Bayona (1808), Madrid, Iustel, 2007, p. 32).

4 Real Orden y Decreto comunicando la proclamación de José I como rey de España (cit. por FERNÁNDEZ SARASOlA, op. cit. (nota 3), pp. 132-133).

5 Gazeta de Madrid, 14-6-1808.

6 Sobre la cesión "voluntaria" del poder hecha por la casa Borbón, véanse: escrito de la Junta Suprema de Gobierno de 3 de junio de 1808 y proclama redactada por los diputados de Bayona el 8 de junio. Por orden: Gazeta de Madrid, 7-6-1808, Gazeta de Madrid, 14-6-1808 y Gazeta de Madrid, 3-6-1808.

7 Sobre la renuncia de los Borbones: Reales Decretos de aceptación de la Corona por José I, (cit. por FERnández Sarasola, op. cit. (nota 3), p. 133).

8 Reales Decretos de aceptación de la Corona por José I (cit. por FERnández SARAsola, op. cit. (nota 3), p. 133). Proclama de José en Vitoria el 12 de julio de 1808, Gazeta de Madrid, 16-7-1808. Discurso josefino dirigido a las autoridades, militares, tribunales, etc. el 23 de julio de 1808, Gazeta de Madrid, 24-7-1808.

9 Reales Decretos de aceptación de la Corona por José I, (cit. por Fernández SARAsola, op. cit. (nota 3), p. 133).

10 Gazeta de Madrid, 17-6-1808.

11 Gazeta de Madrid, 3-2-1809. 
seducir a los españoles, no tardó en publicitar su plan de mejoras y en mayo de 1808, además de prometer una renovación institucional ordenada y tranquila, se comprometió a reflotar la monarquía, devastada, según denunciaba, por el mal gobierno de los antiguos reyes. Bonaparte se presenta ya entonces como el salvador de los destinos de los españoles en contraposición a la casa Borbón, causante, según señalaba, de todos los males de la nación. Por ello defiende la llegada de su dinastía como una necesidad y supedita el progreso de España al mantenimiento de su clan. La nación precisaba una política regeneradora y solo "Napoleón y su otro Yo mismo", es decir, José I, estaban preparados para dirigir el cambio ${ }^{12}$. Pero Napoleón no fue el único que defendió este mensaje. El 3 de junio de 1808, apenas una semana después de que el emperador se refiriese a su plan regenerador, la Junta Suprema de Gobierno se apropió del discurso y defendió también la necesidad de modernizar la monarquía:

Cuando la España, esta nación tan favorecida de la naturaleza, empobrecida, aniquilada y envilecida a los ojos de la Europa por los vicios y desórdenes de su gobierno, tocaba ya al momento de su entera disolución. [...] El Príncipe más poderoso de Europa ha recibido en sus manos la renuncia de los Borbones; no para añadir nuevos países a su imperio, ya demasiado grande y poderoso, sino para establecer sobre nuevas bases la monarquía española, y para hacer en ella todas las reformas saludables, porque tanto suspirábamos hace algunos años, y que solo puede facilitar su irresistible poder. [...] formará leyes fundamentales que aseguren la autoridad del Soberano y la felicidad de los vasallos; y ceñirá con la diadema de España las sienes del Príncipe generoso, [...] y que teniendo en su mano medios y recursos que otro ninguno puede reunir en poco tiempo, restituirá a España el poder que ha perdido por la debilidad de su antiguo gobierno. [...] el héroe que admira el mundo, y admirarán los siglos, está trabajando en la grande obra de nuestra regeneración política $[\ldots]^{13}$.

La Junta sigue el planteamiento del emperador y después de criticar la gestión de la casa Borbón ampara la refundación de la monarquía en manos napoleónicas. Sus miembros sostienen la regeneración política como única alternativa para recuperar la prosperidad de la nación y advierten que la opción contraria, además de aniquilar la monarquía, dejaría a los españoles sumidos en la más absoluta anarquía. Luego, la Junta insiste en los deseos de prosperidad y felicidad de Napoleón y José e incorpora parte de su programa reformador. Entre las principales medidas anuncian el restablecimiento de las Cortes como baluarte de libertad, una justicia sujeta a reglamentación, el progreso del ejército y la marina, y un conjunto de medidas económicas encaminadas a la recuperación del esplendor perdido ${ }^{14}$.

El 8 de junio de 1808 los diputados reunidos en Bayona se postularon igualmente a favor del proyecto modernizador y supeditaron el progreso de España a la presencia de José en el trono. Esta iniciativa, sin embargo, carecía de espontaneidad al haber partido de Napoleón ${ }^{15}$. En cualquier caso, los firmantes de la proclama, que reco-

12 Gazeta de Madrid, 3-6-1808.

13 Gazeta de Madrid, 7-6-1808.

14 Archivo del Congreso de los Diputados, Papeles secretos de Fernando VII, vol. III, pp. 197-198.

15 Los diputados en cuestión fueron: el conde de Orgaz, Manuel de Lardizabal, Vicente Alcalá Galiano, Sebastián de Torres, Antonio Romanillos, el duque de Híjar, el duque del Infantado, el marqués de Santa 
nocían haber respaldado antes a la familia Borbón, defienden ahora la candidatura josefina como única vía para restablecer el poder y la riqueza:

Si trata de modificar y enmendar en la parte que lo exija nuestra antigua legislación, es para que vivamos en razón y justicia: si desea que nuestro Erario público se organice, es para que nuestro Ejército y Marina sean poderosos y temibles a nuestros enemigos, evitando gastos superfluos, dictando una administración sabia que los corrija, animando la industria nacional, cortando las trabas infinitas que detienen a nuestro comercio, y aliviándolo en la parte posible de los pesados e indiscretos tributos que nos han agobiado hasta aquí, y han aniquilado nuestra agricultura y todos nuestros recursos [...] la salud pública no puede ya depender de este momento sino de que todos nos reunamos de corazón al nuevo gobierno, y le ayudemos en la regeneración $[\ldots]^{16}$.

Los de Bayona justifican las reformas de la dinastía entrante, pero tampoco desaprovechan la oportunidad para criticar la gestión de los anteriores reyes y denuncian que el "gobierno caprichoso, indolente e injusto" de los Borbones había causado la "situación lastimosa" en la que se encontraba la nación ${ }^{17}$. De nuevo se vuelve a desacreditar el reinado anterior para defender la necesidad de modernizar España.

Tras la inauguración de la Asamblea de Bayona el 15 de junio de 1808 se multiplicaron las declaraciones de los diputados a favor de la regeneración de la nación. El primero en hacerlo fue Miguel Josef de Azanza, su presidente ${ }^{18}$. El equilibrio político y social estaba prácticamente destruido y la monarquía andaba "próxima a una absoluta ruina". La gravedad de la situación requería grandes soluciones, y no fueron pocos quienes, como Manuel García de la Prada, representante del Banco Nacional de San Carlos, señalaron que "era preciso una mano poderosa que libertase a tan bello país del precipicio en que iba a caer". Según el diputado, Napoleón era el único capaz de elevar la monarquía "al honroso lugar que le correspondía"19. Las críticas sobre la incompetencia de la casa Borbón también aumentaron después de la apertura de la Asamblea. En el discurso inaugural Azanza se refirió a ello en los siguientes términos:

Siglos hacía que estábamos del todo separados de su gobierno; y este confiado a veces a hombres astutos, que no pensaban si no en encadenar con artería a su pueblo; y a veces a débiles y sin carácter, para quienes reinar, no era más que vivir entregados a sus pasatiempos, y abandonar el mando a sus validos. Por estos ha venido la nación española a caer del altísimo puesto a que fue elevada en los siglos XV y XVI, hasta

Cruz, el conde de Fernan-Nuñez, duque de Montellano y del Arco, el duque de Osuna, Josef Colón, el conde de Santa Coloma y de Fuenclara, Raimundo Ettenhart y Salinas, Zenon Alonso, Francisco Amorós, Pedro de Torres, Ignacio de Tejada, Pedro de Porras, Andrés de Herrasti, Cristóbal de Góngora, Luis Idiaquez, el duque del Parque, Domingo Cerviño, Pedro Cevallos y Miguel Josef de Azanza.

16 Gazeta de Madrid, 14-6-1808.

17 Gazeta de Madrid, 14-6-1808.

18 Gazeta de Madrid, 21-6-1808.

19 Diario de Sesiones del Congreso de los Diputados [Recurso electrónico]: Actas de Bayona, Observaciones sobre el Proyecto de Constitución, Madrid, Congreso de los Diputados, 2000, p. 88. 
el abismo en que se hallaba sumida cuando el último de nuestros Reyes ha cedido el derecho de gobernarla a un Príncipe $[\ldots]^{20}$.

Pero el presidente Azanza no fue el único que manifestó su oposición. Fermín Ignacio de Benuza, diputado del clero del obispado de Segovia, señaló que las prácticas despóticas de los antiguos soberanos habían lastrado el progreso de la monarquía ${ }^{21}$. El conde de Fernan-Nuñez, presente también en Bayona, denunció la arbitrariedad de los gobiernos anteriores y sugirió que la nueva Constitución evitaría esos abusos, y el duque de Frías mostró su tristeza y sorpresa al comprobar el estado de decadencia en el que se encontraba la monarquía española ${ }^{22}$. Manuel Romero, diputado del Consejo de Hacienda, se hizo eco igualmente del despotismo y capricho de los Borbones: "conviene en efecto que la España, que no ha conocido otro gobierno que el que ha dictado el capricho momentáneo y el más horrible despotismo, vea cuanto antes los fundamentos de su próxima prosperidad, y entienda que va a sacudir las tinieblas que han tenido sepultados sus derechos" 23 . El 8 de julio de 1808, finalizadas las reuniones, Azanza volvió a referirse a la degeneración de la España borbónica en el discurso de gratitud ante Napoleón por la aprobación de la Constitución de Bayona:

El orden social estaba a punto de disolverse entre nosotros; el Gobierno superior lo había atraído todo a sí, para ensanchar más los límites de la arbitrariedad, escoger los negocios en que pudieran hacerse lugar la parcialidad ó el capricho, y dejar los demás en abandono [...] La Hacienda era verdaderamente un caos, y la deuda pública un abismo. Los resortes todos de la administración estaban dislocados y rotos; no había parte sana que ejerciera con regularidad sus funciones $[\ldots]^{24}$.

José Bonaparte, por su condición de rey, también incorporó la necesidad de regenerar la monarquía a sus discursos. La primera referencia la hizo en Marrac el 7 de junio de 1808, después de escuchar el discurso de bienvenida de Azanza. Según publicó la Gazeta de Madrid, José le comunicó: "estaría satisfecho si el resultado de sus tareas era el restablecimiento del orden en el erario, la reorganización del ejército y de la marina; y sobre todo, si bajo su gobierno la España volvía al libre goce de sus privilegios y constituciones" 25 . Una vez aprobada la Constitución, José destacó su importancia como símbolo de regeneración política, y el 8 de julio de 1808, día de su entrega a los diputados, el monarca defendió nuevamente sus beneficios y planteó el documento como parte esencial de su programa para liberar a los españoles ${ }^{26}$. El 12 de julio siguiente, José insistió desde Vitoria en las mejoras de la Constitución:

20 Gazeta de Madrid, 21-6-1808.

21 Diario de Sesiones del Congreso de los Diputados, op. cit. (nota 19), p. 103.

22 Diario de Sesiones del Congreso de los Diputados, op. cit. (nota 19), p. 77. Para el caso del duque de Frías: Archivo del Congreso de los Diputados, Papeles secretos de Fernando VII, vol. IV, pp. 18-20.

23 Diario de Sesiones del Congreso de los Diputados, op. cit. (nota 19), p. 83.

24 Junta Duodécima, 8-7-1808. Diario de Sesiones del Congreso de los Diputados, op. cit. (nota 19), pp. 47-50.

25 Gazeta extraordinaria de Madrid, 12-6-1808.

26 Junta Duodécima, 8-7-1808. Diario de Sesiones del Congreso de los Diputados, op. cit. (nota 19), pp. 47-50. 
Hace revivir vuestras antiguas cortes, mejor establecidas ahora; instituye un senado que, siendo el garante de la libertad individual, y el sostén del trono en las circunstancias más críticas, será también, por su propia reunión, el asilo honroso con cuyas plazas se verán recompensados los más eminentes servicios que se hagan al estado. Los tribunales, órganos de la ley, impasibles como ella misma, juzgarán con independencia de todo otro poder. El mérito y la virtud serán los solos títulos que sirvan para obtener los empleos públicos $[\ldots]^{27}$.

En adelante el monarca se referirá a menudo a su compromiso de hacer felices a los españoles. José quiere dar la imagen de rey comprometido e incorpora esta máxima en sus discursos. La primera referencia la hizo en el decreto de aceptación del trono el 10 de junio de $1808^{28}$. Pero en España el rey sigue avivando su compromiso con una intencionalidad política. La primera vez, el 12 de julio, de camino a Madrid ${ }^{29}$. El 22 de enero de 1809, en el discurso que leyó en Madrid en la iglesia de San Isidro insistió igualmente en su deseo de fomentar la felicidad ${ }^{30}$. José destacó este punto siempre que pudo para captar el apoyo del pueblo y demostrar que las políticas abusivas de los Borbones eran cosa del pasado.

\section{El fracaso de la casa Borbón, el éxito de los Bonaparte}

Napoleón, José y sus hombres informaron en las proclamas de su perfil reformador y de la conveniencia de aplicar sus políticas regeneradoras para salvar la monarquía. La publicación de esos papeles en la Gazeta de Madrid, convertido en periódico oficial del régimen, demuestra el interés de la dinastía por publicitar el cambio. Pero la campaña de propaganda a favor de la regeneración no se redujo a ello y los medios periodísticos también incorporaron artículos que defendían la política modernizadora, sobre todo en los momentos de mayor inestabilidad del gobierno. El enfoque de estos trabajos, sin embargo, no fue nuevo. Las plumas josefinas siguieron el patrón de las proclamas oficiales y defendieron el proyecto renovador basados en tres puntos: el progreso que se conseguiría con los Bonaparte, la ineficiencia de la casa Borbón, y el reformismo de la Constitución de Bayona. En realidad, la propaganda se mostró más interesada en recalcar los desastres de la monarquía saliente que las ventajas de la nueva, al menos hasta que se empezaron a apreciar los avances, ya en 1809. La incapacidad de los Borbones para reinar, su nefasta gestión y su nulo interés por las tareas de gobierno y por sus súbditos, fueron algunos de los argumentos esgrimidos para defender su destronamiento de España. La Gazeta de Madrid fue uno de los periódicos más combativos con la antigua administración. Su control josefino durante casi toda la contienda garantizaba un ataque sistemático ${ }^{31}$. Esta política de

27 Gazeta de Madrid, 16-7-1808.

28 Reales Decretos de aceptación de la Corona por José I, (cit. por Fernández Sarasola, op. cit. (nota 3), p. 133).

29 Gazeta de Madrid, 16-7-1808.

30 Gazeta de Madrid, 23-1-1809.

31 La Gazeta de Madrid estuvo controlada durante casi toda la guerra de la Independencia por los josefinos, a excepción de breves períodos. A finales de julio de 1808, por ejemplo, tras la derrota de Bailén, José huyó de 
descrédito obedecía a los planes de Napoleón, que ya en abril de 1808 había ordenado al lugarteniente Murat artículos que informaran de la mala situación en la que se encontraba la nación. Recuérdese que el control de la prensa era uno de los objetivos principales del emperador en los países que iba ocupando ${ }^{32}$. Todo esto explica que la primera imagen difundida por el periódico no aludiese al carácter bondadoso, paternal, católico, etc. de José, ni siquiera al propio Napoleón, sino a la imagen de España como nación en decadencia. En junio de 1809 los redactores de la Gazeta de Madrid, antes de defender la política reformadora de José se refirieron al desastroso escenario existente a su llegada. La debilidad, tiranía y corrupción de los Borbones justificaba la necesidad de transformar todos los ramos del gobierno ${ }^{33}$. Otro rotativo crítico con la gestión de los viejos reyes fue El Imparcial. Pedro Estala, su redactor, firmó varios artículos en los que reprochaba su despotismo y mal gobierno ${ }^{34}$. El primero, titulado Discurso sobre la Constitución, fue publicado a partir del 21 de marzo de $1809^{35}$. Estala, defensor acérrimo de la Constitución, acusó a la antigua dinastía de haber robado a los españoles "las leyes fundamentales" que habían servido para atar "las manos a los príncipes" ${ }^{36}$. El canónigo se remonta al reinado de Felipe V, al que acusa de completar la opresión iniciada por la dinastía austríaca: "Esto quiero, esto mando, ha sido la ley suprema y la única constitución que hemos tenido durante la dinastía borbona" ${ }^{37}$. Luego señala algunas de las consecuencias del sistema tiránico que oprimía al pueblo español:

La despoblación, la miseria, la falta de toda industria, el abandono de los campos y talleres, y la opresión más completa. De aquí nuestra nulidad en el sistema político de Europa; desorganizado nuestro ejército, destruida nuestra marina, aniquilado nuestro comercio, y lo que es aun peor, envilecidos los ánimos hasta el extremo de hallarnos bien con nuestra ignorancia, esclavitud y abatimiento ${ }^{38}$.

\footnotetext{
Madrid y el rotativo quedó bajo el control ideológico de los patriotas hasta que en diciembre de 1808 la capital fue reconquistada por las tropas napoleónicas. Sobre la importancia de la Gazeta de Madrid como instrumento de propaganda véanse los siguientes trabajos de Gérard Dufour: «La prensa ocupada por los franceses», en La PARRA, Emilio (ed.): La Guerra de Napoleón en España. Reacciones, imágenes, consecuencias, Alicante, Universidad de Alicante, Casa de Velázquez, 2010, pp. 135-148. "La Gazeta afrancesada de Madrid" (18081813), en Cuadernos de Ilustración y Romanticismo. Revista Digital del Grupo de Estudios del Siglo XVIII, $\mathrm{n}^{\circ}$ 16, (2010), http://diana.uca.es/search $\sim \mathrm{S} 7$ *spi?/XDUFOUR\&searchscope=7\&SORT=D/XDUFOUR\&sear chscope $=7 \&$ SORT $=$ D \&SUBKEY $=$ DUFOUR $/ 1,173,173, \mathrm{~B} / 1856 \sim \mathrm{b} 3544514 \& \mathrm{FF}=\mathrm{XDUFOUR} \&$ searchscope $=$ 7\&SORT=D\&11,11,1,0 [Consulta: 1 diciembre 2011].

32 El 30 de abril de 1808 el emperador escribió desde Bayona a su lugarteniente que suponía "que ya se ha adueñado de la Gaceta de Madrid y que cada día hace publicar artículos en ella". LeCESTRE, León (ed.): "La guerre de la Péninsule (1807-1813) d'après la correspondance inédite de Napoléon I", en La Revue des Questions Historiques, trente-septième année, nouvelle série, t. XV (LIX de la Collection), 1896, p. 461.

33 Gazeta de Madrid, 29-6-1809.

34 Sobre el papel de Pedro Estala como defensor de la regeneración josefina: LARRIBA, Elisabel: El Imparcial o Gazeta política y literaria (21 de marzo de 1808 - 2 de agosto de 1809), CSIC, 2010.

35 El artículo fue publicado en El Imparcial de forma fragmentada desde el 21 de marzo hasta el 4 de abril de 1809 en los números $1,2,3$, y 5.

36 El Imparcial, 21-3-1809.

37 El Imparcial, 4-4-1809.

38 El Imparcial, 24-3-1809.
} 
Estala reconocía que lo deseable habría sido que los españoles no hubiesen necesitado ayuda exterior para acabar con el yugo que les oprimía y que el establecimiento de la Constitución se hubiese alcanzado por los mismos procedimientos. Sin embargo, concluía que dado el despotismo de los Borbones los españoles no habrían recobrado su libertad sin la intervención imperial. Patriotismo es el título de otro artículo en el que Estala también atiza a la casa Borbón ${ }^{39}$. En este acusa a los reyes de obstruir la industria, fomentar la concentración de las propiedades y ampliar las diferencias entre patrones y serviles ${ }^{40}$.

En unas ocasiones la propaganda josefina desprestigió la gestión de sus antecesores y en otras puso de relieve los buenos propósitos de la nueva. Pero a menudo también publicaron extractos en los que se comparaban las políticas antagónicas puestas en marcha por ambas monarquías. De esta forma se sospechaba que los españoles se percatarían antes de la necesidad del cambio. Pedro Estala lo hizo en El Imparcial el 9 de mayo de 1809: "S. M. se ocupa incesantemente en proveer a las necesidades más urgentes del estado, y en preparar los medios más eficaces para curar radicalmente las profundas heridas que ha causado a la nación el mal gobierno anterior y los desórdenes de la anarquía pasada"41. Estala primero subraya la capacidad de trabajo de José, su responsabilidad y su implicación directa en todas las tareas de gobierno:

Despacha [José] diariamente con los ministros respectivos los varios asuntos del gobierno. Estos despachos no tienen ninguna semejanza con los del antiguo gobierno, que se reducían a dar una cuenta rápida en pocos minutos de los negocios más importantes, y dar unas resoluciones de rutina, o tan ruinosas como inconsideradas. Además de los despachos ordinarios con los ministros respectivos, tiene S. M. consejo con todos ellos, a lo menos dos veces a la semana, en donde por espacio de muchas horas delibera S. M. sobre todo lo que va ocurriendo [...] De este modo el Soberano se informa fundamentalmente del estado de todos los ramos; oye los dictámenes de sus ministros $[\ldots]^{42}$.

Seguidamente describe el sistema anterior para enfatizar los beneficios de la regeneración política. La vagancia de los viejos reyes se convierte en la crítica principal. Estala apuntó que en la época de los Borbones cada ministro era un rey y que su voluntad era tan despótica como la del monarca más absoluto. Los abusos de los ministros, declaraba, eran efecto de la pereza de los reyes y del desprecio y abandono con que miraban las obligaciones de su cargo. Los soberanos estaban convencidos de que los pueblos "eran una propiedad suya de la misma naturaleza que un rebaño de ganado" y no anteponían la tarea de gobierno a sus diversiones. Las obligaciones de Estado no era lo más importante para los soberanos, que cedían gustosamente el cetro a sus ministros. Estala seguía su particular escarnio explicando que el recreo del rey, como el que cualquier otro individuo, era una necesidad para el desahogo de su ánimo, pero matizaba que eso era una cosa, y otra hacer de la diversión su única ocupación. El canónigo concluía que esa situación había sido corriente hasta el

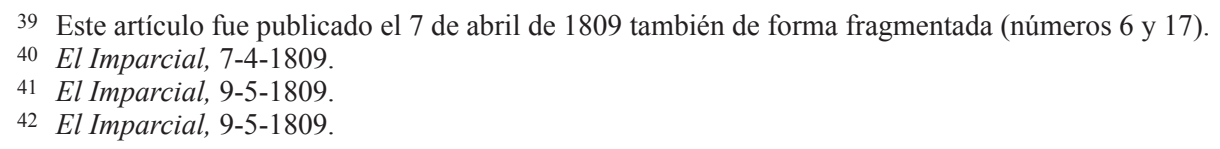


momento, pero descartaba su mantenimiento con la llegada de José: "Cuando todos los pueblos del imperio español tengan una noticia exacta del uso que hace nuestro monarca de su tiempo y de sus talentos, no podrán menos de pagarle el justo tributo de amor y alabanza a que cada día se hace más acreedor".

Las diferencias que representaban ambas monarquías fueron incorporadas también en muchos discursos de las autoridades josefinas ${ }^{43}$. La carga publicitaria de estos documentos era menor, pues la mayoría no habían sido escritos para ser publicados en la prensa -al menos inicialmente-, pero no estaban exentos de intencionalidad política. Es el caso de la carta enviada por el ministro Urquijo al obispo de Orense el 8 de septiembre de 1808. El ministro recordaba las dificultades de la España de los Borbones, y advertía que el fracaso de la nueva dinastía perpetuaría la ruina económica, el despotismo, los abusos y la arbitrariedad legislativa. La carta enviada ese mismo día por Urquijo al gobernador del Consejo de Castilla también subrayaba los contrastes de las dos dinastías: "En fin, queda muy poco tiempo para optar entre la guerra o la paz, la constitución o la conquista, la anarquía o un rey [...]"44. En febrero de 1810, con motivo de la llegada de José a Sevilla, Nicolás Maestre, canónigo de la catedral, defendió ante sus feligreses que José representaba una realidad distinta con el pasado inmediato: "al pavor sucedió la serenidad; a la confusión el buen orden" 45 . El 18 de febrero de 1810, Antonio Posada, canónigo de la iglesia madrileña de San Isidro, recalcó la importancia del cambio:

El cielo, que hasta aquí presentó un sañudo aspecto, se despeja insensiblemente, y su bella alborada es precursora de una felicidad sólida y verdadera. A tantas escenas de miseria y calamidades sucede el genio benéfico de la paz, y la esperanza halagüeña de un gobierno sabio y cristianamente filósofo, que más de una vez nos ha libertado ya del precipicio, y prevenido nuestra ruina ${ }^{46}$.

José González Aceijas, párroco de Sevilla, también constató las diferencias de las dos dinastías en el sermón que hizo en acción de gracias por la llegada de José a la capital hispalense: "Al desorden sobrevino la disciplina; al insulto la obediencia: a la antigua arbitrariedad la publicación de las leyes que para nuestra felicidad había establecido. En conclusión al abismo de los males en que yacíamos, sucedieron los bienes" ${ }^{47}$. La comparación Bonaparte-Borbón es evidente en todos los casos, y su componente promocional a favor de los primeros, lo mismo, algo normal si se tiene en cuenta el uso del púlpito como tribuna política para atraer a los españoles a la causa josefina.

43 Para un conocimiento más amplio de este punto, véanse: FERnÁndez Sirvent, R., "Por la regeneración de España. El ideario político de un funcionario josefino: Francisco Amorós”, Trienio, 45 (2005), pp. 5-19; LÓPEZ TABAR, J., Los famosos traidores. Los afrancesados durante la Crisis del Antiguo Régimen (1808-1833), Madrid, Biblioteca Nueva, 2001; y LuIs, J.-Philippe, "El afrancesamiento, una cuestión abierta", Ayer, n86 (2012), pp. 89-109.

44 Urquijo al gobernador del Consejo de Castilla, 8-9-1808 (Du CAsse, A.: Mémoires et correspondance politique et militaire du roi Joseph, París, Perrotin, Libraire-Editeur, 1834, vol. V, pp. 57-59).

45 Gazeta de Madrid, 18-2-1810.

46 Gazeta de Madrid, 19-2-1810.

47 González AceiJas, José: Sermón que hizo en acción de gracias por la venida del rey nuestro señor don José Napoleón I a Sevilla, Puerto de Santa María, Impr. por D. Fernando de Luque y Leiva. 
Después de describir la situación en la que se encontraba la monarquía con la familia Borbón, la propaganda elogió a la nación francesa como paradigma para España. La Francia de Napoleón, símbolo de riqueza, ilustración, democracia, justicia y un sinfín de virtudes más, era presentada como la única esperanza a la que debían aferrarse aquellos países que, como España, aún no habían experimentado esas ventajas por la incompetencia de sus viejos reyes.

En buena parte de los papeles en los que se habla de la necesidad de regenerar la monarquía antes o después se acaba criticando la gestión de la casa Borbón. Primero Napoleón y José lo hacen en sus discursos, pero luego el servicio de propaganda mantiene el recuerdo del fracaso borbónico. La propaganda mantuvo el discurso imperial e identificó la España josefina con el orden, la justicia, la felicidad, el progreso, la libertad, etc. y a la llamada España patriótica, la de los antiguos reyes y sus partidarios, con el caos, el despotismo, la miseria, la corrupción, etc. Las plumas napoleónicas dibujaron un retrato bicéfalo de la monarquía en la que enfrentaban el bien, encarnado por José, y el mal, que se identificaba con la casa Borbón. Esta visión dicotómica, que presenta a los Bonaparte como salvadores en contraposición con sus predecesores, enlaza con la descripción del mito del reino feliz del final de los tiempos planteado por García-Pelayo:

Al final del tiempo vendrá un reino feliz en el que la humanidad se verá libre de los problemas que le agobian, un reino en el que regirá la justicia y, por ella, la paz, en el que habrá prosperidad económica y en el que la angustia desaparecerá de los corazones. En una palabra, un orden coincidente con el hombre, y en el que, por tanto, éste será feliz ${ }^{48}$.

El ataque sistemático a los antiguos reyes formaba parte de la campaña diseñada para legitimar la necesidad de corregir los vicios de la monarquía. La demonización de los Borbones engrandece la imagen de José pero, sobre todo, confirma la necesidad de ejecutar su proyecto regenerador. La familia Bonaparte se presentaba como un milagro que evitaría la destrucción de la nación. La coronación de José formaba parte del plan regenerador, pero la renovación de la monarquía debía ser más profunda para conquistar el esplendor perdido.

Aunque en menor medida, la opción josefina, Constitución de Bayona incluida, también fue puesta en valor. Los periódicos de la corte insistieron en el equilibrio institucional que representaba el texto, al tiempo que hicieron hincapié en sus propiedades regeneradoras ${ }^{49}$. La prensa recogió el planteamiento de Miguel de Azanza y destacó la capacidad de la Constitución para estimular el bienestar de la monarquía ${ }^{50}$. El compromiso de la Gazeta de Madrid y El Imparcial a favor de la Constitución fue

48 García-Pelayo, Manuel: Mitos y símbolos políticos, Madrid, Taurus, 1964, p. 12.

49 El Imparcial, 21-3-1809 y 14-4-1809.

50 “¿Y cuánto no lo será á V. M. cuando le vea dedicado enteramente á organizar su gobierno, restablecer su Hacienda, vivificar su comercio, crear su industria é indicarle los caminos; que había desconocido de la prosperidad y de la gloria? V. M. le ha anunciado, y le anuncia ahora, que le conducirá por ellos: la Constitución acredita que lo desea, y las pruebas de V. M. tiene dadas de que conoce el arte difícil de reinar, no deja duda de que ha de cumplirlo". Junta Duodécima, 8-7-1808, Diario de Sesiones del Congreso de los Diputados, op. cit. (nota 20), pp. 47-50. 
notable. A veces lo hicieron sus redactores, pero en otras ocasiones estos periódicos incorporaron testimonios de individuos influyentes como el de José Ignacio Joven de Salas. Este consejero de Estado definió la Constitución como un "libro de la felicidad" capaz de reparar los estragos y abusos de la monarquía. Joven de Salas admitía en la Gazeta de Madrid que España se encontraba al borde del abismo, pero reconocía que la Constitución cambiaría el panorama. Pedro Estala también se postuló a favor del cambio constitucional y explicó su utilidad en el Discurso sobre la Constitución. El canónigo expuso que el texto garantizaría la libertad, el orden, la justicia, la abundancia, la felicidad, etc. incluso desaparecido el monarca ${ }^{51}$. Después el turno le llegó a José Bonaparte. La prensa lo asoció a menudo con el adelanto de España para poner en positivo su imagen pública. La propaganda ensalzó su figura durante toda la contienda, pero aumentó sus esfuerzos en momentos clave. Por ejemplo, cuando hizo su entrada en Madrid en enero de 1809 tras la reconquista de la capital, o cuando en 1810 llegó a Granada ${ }^{52}$. En ambos casos la prensa ensalzó su figura como restablecedor de la monarquía. Pocos días antes de la llegada de José a Granada la Gazeta del Gobierno de Granada dio cuenta del carácter salvador del rey: "Granadinos: José I es el rey que pedían vuestros votos; José $\mathrm{I}^{\mathrm{o}}$ el que gritaban vuestros vivas al sentir el peso de vuestras desgracias; José $\mathrm{I}^{\mathrm{o}}$ el que viene a poner un término a vuestros males, y a ser el principio y autor de vuestra felicidad, y el restablecedor de nuestra monarquía" 53 .

\section{Regeneración en época de guerra}

La llegada de José a España inauguró una etapa plagada de reformas. A pesar de las adversidades de la guerra, el monarca se esforzó por modernizar la estructura del Estado y diseñó un ambicioso corpus legislativo siguiendo el modelo napolitano (1806-1808). La Constitución de Bayona representó la consumación del cambio político, pero el proyecto modernizador contemplaba innovaciones en el ámbito de la economía, (industria, agricultura, comercio, transporte, etc.), la educación, la cultura, la ciencia, el urbanismo, la asistencia pública, etc. ${ }^{54}$. La aplicación de estas reformas estuvo sujeta a los vaivenes de la guerra y muchas nunca vieron la luz, pero el deseo de José de regenerar la monarquía fue sincero.

La esfera económica concentró buena parte de las medidas regeneradoras del gobierno. La ruinosa situación económica por la que atravesaba la monarquía había sido motivo de crítica, así que su reparación se convirtió en uno de los objetivos principales de la dinastía. Las promesas económicas hechas por José el 12 de julio de 1808 no tardaron en ver la luz: "Si mis deseos no me engañan, pronto florecerán vuestra agricultura y vuestro comercio, libres para siempre de las trabas fiscales que

51 El Imparcial, 24-3-1809 y 7-4-1809.

52 Gazeta de Madrid, 21-1-1809 y 16-2-1810.

53 Gazeta del Gobierno de Granada, 9-3-1810.

54 Sobre el avance de la monarquía en materia asistencial: Gazeta de Madrid, 9-5-1810 y 27-8-1809, y Archivo General de Palacio, Real Capilla, Caja 44 y 45. 
le destruyen [... $]^{55}$. El entramado legislativo diseñado en la época da muestra del grado de renovación previsto. La agricultura, la industria y el comercio, principales motores económicos de la nación, concentraron el grueso de las mejoras. José I promovió una política liberalizadora ambiciosa y suprimió parte de los impuestos. Los dos primeros decretos liberalizadores fueron publicados en febrero de 1809 y buscaban promover el "progreso de la industria nacional" y el "adelantamiento de la agricultura". El primero, sancionado el día 3, contemplaba la libre fabricación, circulación y venta de naipes, y el segundo, fechado el 15 de febrero, fijaba lo mismo para los aguardientes ${ }^{56}$. En los meses siguientes se eliminaron otros gravámenes. El 1 de marzo de 1809 se suprimió el derecho de tanteo por "ofender la propiedad real e industrial" y perjudicar "a las artes y fábricas" 57 , el 20 de junio se liberalizó la circulación del azufre de las minas, y el 6 de septiembre el del solimán y el lacre ${ }^{58}$. Pero la eliminación de impuestos no fue la única medida regeneradora que se llevó a cabo. Las autoridades facilitaron el arriendo de las tierras incultas para fomentar la riqueza nacional ${ }^{59}$. En materia de industria, el gobierno se deshizo de algunas de las ruinosas fábricas nacionales. La cesión de las fábricas de cristales de San Ildefonso a favor de la industria pública respondía a esto y al deseo de impulsar la industria privada ${ }^{60}$. El proyecto de fundar fábricas en las casas de religiosos (Zaragoza, 11 de marzo de 1809), la instalación de varias industrias en Málaga o el establecimiento en Madrid de un taller de óptica (11 marzo de 1810) ilustra el afán industrialista y la predisposición privatizadora de la dinastía ${ }^{61}$. Para dinamizar el comercio, además de las medidas liberalizadoras, se estableció en Madrid la Bolsa de Comercio (14 de octubre de 1809) y se suprimieron las aduanas interiores ${ }^{62}$. Pero si hubo una medida económica significativa fue la del pago de la deuda pública (decreto de 9 de junio de 1809). El gobierno hizo frente al déficit acumulado vendiendo parte de los bienes nacionales ${ }^{63}$.

El plan modernizador de José transformó el esquema urbano de algunas ciudades españolas. Las dificultades económicas de la guerra lastraron la consecución de muchas obras, pero pese a ello las mejoras fueron numerosas. Por su condición de capital, Madrid acaparó buena parte de las reformas urbanísticas. La creación de espacios abiertos se convirtió en una prioridad, pues además de renovar el aspecto de la capital, mejoraría la salubridad del aire. La apertura de plazas y el ensanchamiento de las calles obedecían a este plan. Una de las zonas remodeladas fue los alrededores del Palacio real. En diciembre de 1809 José decretó el ensanchamiento de la plazuela

55 Gazeta de Madrid, 16-7-1808.

56 Prontuario de las leyes y decretos del rey nuestro señor Don José Napoleón I, Madrid, Impr. Real, 1812, vol. I, pp. 80-81 y pp. 103-104.

57 Ibidem, vol. I, p. 139.

58 Para examinar el decreto sobre el azufre: Ibid., vol. I, pp. 212-213, y para la orden del solimán y el lacre: $I b .$, vol. I, p. 341.

59 En 1809 las tierras de labor, pastos y huertas de los Sitios Reales de Aranjuez y San Fernando fueron arrendadas. Y lo mismo ocurrió con las pertenecientes a los conventos suprimidos y propietarios fugados. Prontuario..., op. cit. (nota 55), vol. I, pp. 328-330.

60 Prontuario..., op. cit. (nota 56), vol. I, pp. 353-355.

61 Ibidem, vol. I, pp. 154-155, y pp. 41-42.

62 Ibid., vol. I, pp. 371-377, y pp. 399-400.

63 Para profundizar en el decreto sobre el pago de la deuda pública y los procedimientos para liquidar el déficit: $I b .$, vol. I, pp. 194-198, y pp. 203-208. 
que se formaba delante de su fachada oriental para uso y disfrute de los madrileños ${ }^{64}$. También con el propósito de construir una plaza "en beneficio del público y para adorno de nuestra capital", el 10 de octubre de 1809 se decretó el derribo de las casas situadas detrás de la Real Armería ${ }^{65}$. La demolición de los arcos de comunicación que conectaban una manzana a otra también se hizo en aras del embellecimiento y comodidad de la capital. Estas construcciones, además de facilitar la propagación de los incendios, afeaban y quitaban visualidad y ventilación a las calles. En Andalucía también se abrieron nuevos espacios públicos con motivo de la estancia de José en 1810. El 20 de abril se dispuso la construcción de una plaza en Sevilla en el terreno de la huerta que había pertenecido al convento de San Francisco ${ }^{66}$. A los pocos días se demolieron los edificios situados en el terreno que ocupaba la manzana comprendida entre las plazas de la Regina y de la Encarnación para la construcción de una segunda plaza $^{67}$. Buena parte de las mejoras urbanísticas se hicieron para hermosear la estética de las ciudades, pero otras, en cambio, tuvieron un destino más funcional. La construcción en 1809 de tres cementerios a las afueras de Madrid -entonces solo había uno- y un mercado de pescado respondía al interés de José por mejorar la higiene pública, y lo mismo el sellado de la alcantarilla del Prado ${ }^{68}$. El arreglo de los caminos entre Granada y Jaén o la mejora del recinto portuario de Málaga en marzo de 1810 obedecían al mismo interés ${ }^{69}$.

La esfera educativa tampoco quedó al margen de la política regeneradora de José Bonaparte. La dinastía promovió la instrucción pública para que los españoles recibiesen una formación ilustrada. La supresión de las órdenes regulares en agosto de 1809 apartó a los escolapios de la enseñanza, pero la primera instrucción no sufrió ningún trastorno por ello, pues la desaparición de las Escuelas Pías fue suplida mediante la fundación de colegios de Pensionistas y escuelas gratuitas ${ }^{70}$. El 17 de enero de 1810 se creó un colegio de primera enseñanza para niños en el convento de Santo Domingo, en Almagro (Ciudad Real). Y al mes siguiente se decretó la instalación de otro en Sevilla dotado con 100.000 reales anuales ${ }^{71}$. A los alumnos de las escuelas se les enseñaría a leer, a escribir y nociones básicas de aritmética, y los estudiantes de los colegios aprenderían además gramática castellana, principios de álgebra y geometría, dibujo y geografía y geometría descriptiva. Otro decreto de 26 de octubre de 1809 fijaba que en cada capital de Intendencia se estableciese un colegio denominado liceo. Su acceso, no obstante, estaba limitado a los alumnos mantenidos por el Estado, a los pensionistas inscritos por sus padres y a los escolares externos matriculados para asistir solo a las lecciones ${ }^{72}$. José también quiso que las mujeres se beneficiaran de la educación pública y el 29 de diciembre de 1809 decretó la fundación de una

64 Ib., vol. I, pp. 441-442.

$65 \mathrm{Ib}$., vol. I, pp. 365-366.

66 Gazeta de Madrid, 7-5-1810.

67 Gazeta de Madrid, 15-5-1810.

68 Por orden, Prontuario..., op. cit. (nota 56), vol. I, pp. 146-148, y 436-437. Archivo Histórico Nacional, Estado, legajo 3.113 (sin foliar).

69 Prontuario..., op. cit. (nota 56), vol. II, pp. 54-56, y pp. 40-41.

70 Ibid., vol. I, pp. 337-339.

71 Ib., vol. II, pp. 11-13, y pp. 34-36.

72 Ib., vol. I, pp. 417-430. 
casa de educandas en cada provincia, aunque el plan de estudios sería distinto al de los niños. Las jóvenes, además de la lectura, la escritura y la doctrina cristiana debían aprender a coser, a bordar y adquirir todas "las demás habilidades que constituyen la buena educación de una mujer"73. Cada casa tendría una renta anual de 150.000 reales, pero solo serían admitidas las niñas nombradas por el rey y aquéllas cuyas familias pagaran los gastos de su matrícula. El 12 de febrero de 1810 se decretó la instalación en Sevilla de una de estas instituciones, y en 1811 se fundó otra en el convento de San José, en La Solana (Ciudad Real) a cargo de las monjas dominicas, pese a contravenir las disposiciones a favor de la educación secularizada ${ }^{74}$.

En el ámbito de la cultura y la ciencia el avance fue igualmente notable. Los decretos ilustran el interés de José por salvaguardar y potenciar la esfera del saber. La ampliación del Jardín Botánico de Madrid (decreto de 18 de febrero de 1809) y la fundación de una escuela para incrementar la productividad agrícola obedecen a ello $^{75}$. Y los trabajos para la publicación de los resultados de la expedición botánica de Nueva España lo mismo ${ }^{76}$. En el plano cultural, el proyecto más importante fue la formación de un Museo de Pintura que reuniera en un único espacio la riqueza pictórica de España (20 de diciembre de 1809) ${ }^{77}$. La función sería doble, pues además de protegerse el patrimonio artístico del olvido colectivo, lo rescataría del confinamiento privado para ponerlo a disposición del pueblo. De esta forma, el público, incluso el de los países vecinos, disfrutaría la belleza de obras maestras de Velázquez, Ribera o Murillo. La pinacoteca quedaría instalada en el palacio de Buenavista, en Madrid ${ }^{78}$, pero el mismo 20 de diciembre el gobierno contempló la formación de otra en París. La formación del museo obedece al ideal josefino de centralizar la cultura y las artes en edificios únicos, pero hubo otros proyectos similares para que el pueblo admirase su riqueza patrimonial ${ }^{79}$. En marzo de 1809 en Zaragoza se decretó la concentración de los libros, los manuscritos, las "pinturas y demás efectos concernientes a ciencias y artes" en un edificio, y el 26 de agosto siguiente otra orden fijaba el traslado de los libros pertenecientes a los conventos extinguidos y los de la Biblioteca Real al convento de la Trinidad. Pero José también promovió el mantenimiento y la recuperación del patrimonio monumental y artístico. En febrero de 1810 financió la excavación de las ruinas del anfiteatro de Itálica ${ }^{80}$, y al mes siguiente ordenó la rehabilitación del palacio de la Alhambra de Granada y la terminación de la residencia de Carlos $\mathrm{V}^{81}$.

73 Ib., vol. I, pp. 465-468.

74 Ib., vol. II, pp. 34-36.

75 Ib., vol. I, pp. 133-135.

76 Ib., vol. I, pp. 158-160.

77 Ib., vol. I, pp. 459-461.

78 Ib., vol. II, pp. 204-205.

79 Actas del Consejo Privado de José, 26-8-1809, (cit. por MERCAdER RiBA, Juan: José Bonaparte, rey de España. 1808-1813. Estructura del estado español bonapartista, Madrid, CSIC, 1983, p. 547).

80 Prontuario..., op. cit. (nota 56), vol. II, pp. 27-28.

81 Ibidem., vol. II, pp. 48-49. Sobre las obras acometidas en el recinto nazarí: Archivo General de Palacio, José I, Caja 19-11. 


\section{La Regeneración, arma de propaganda}

La legislación aprobada en materia educativa, económica, cultural, etc. respondía al deseo de José de modernizar los cimientos principales de la monarquía. El espíritu regenerador de la nueva dinastía empezó a circular por España a partir de mayo de 1808. Desde entonces se difundió la necesidad del cambio, pero con la introducción de las primeras reformas el compromiso de la propaganda se hizo más visible. Las imágenes de José como salvador de la economía, "rey filósofo", protector de las artes y las ciencias, etc., demostraba su espíritu regenerador, así que la propaganda las promocionó para favorecer su perfil público ${ }^{82}$. La Gazeta de Madrid se convirtió de nuevo en el medio de comunicación principal para dar a conocer la imagen de "rey regenerador". El periódico incorporó en sus páginas los decretos reformadores con este fin, pero además defendió su idoneidad. Ya fuese una disposición económica, urbanística o educativa, la política regeneradora fue ensalzada por la prensa amiga. Por ello a los pocos días de aprobarse uno de estos decretos se publicaban artículos en los que además de explicar su contenido, se analizaban sus ventajas y se justificaba la necesidad de su implantación en España.

Las primeras medidas defendidas por la Gazeta de Madrid fueron las educativas, aunque sus redactores tuvieron que recurrir inicialmente al ejemplo napolitano. En diciembre de 1808 José no había tomado ninguna decisión en esta materia en España, pero el periódico se adelantó y publicó varios artículos que enumeraban los progresos en Nápoles durante el reinado de José (1806-1808) ${ }^{83}$. La publicación de estos papeles no fue casual, y tampoco los divulgados días después sobre los progresos de la Francia imperial. El 4 de enero de 1809 la Gazeta de Madrid ensalzó la práctica regeneradora de Napoleón. El periódico defendió que su política reformadora había situado la educación del imperio en un puesto de primer orden ${ }^{84}$. Aunque en estos artículos no se trataba específicamente la regeneración de España, su componente publicitario a favor del plan modernizador era evidente. En marzo de 1808 el rotativo ya había incluido noticias sobre el adelanto de las comunicaciones interiores en la etapa de José, aunque estas referencias eran informativas y no tenían el efecto publicitario que ofrecían los artículos publicados a partir de junio de 1808, cuando la Gazeta de Madrid se convierte en el instrumento principal de la propaganda josefina ${ }^{85}$. En marzo de 1808 el periódico alude al avance de Nápoles durante el reinado de José, y en enero de 1809 también, sin embargo, la intencionalidad es distinta, ya que los artículos publicados desde mayo hasta julio de 1808 y, sobre todo, a partir de diciembre, más que informar, ensalzaban la imagen de José como rey regenerador. Los artículos sobre las mejoras de Francia y Nápoles eran un anticipo publicitario de las ventajas que alcanzaría España con la llegada de la nueva dinastía. De los artículos se desprendía

82 Dufour, Gérard: «Le roi philosophe», en Mélanges de la Casa de Velázquez, 38-1, Madrid, Casa de Velázquez, 2008, pp. 53-70.

83 Estos textos fueron publicados en el suplemento de la Gazeta de Madrid desde el jueves 29 de diciembre de 1808 hasta el lunes 2 de enero de 1809. Gazeta de Madrid, 29-12-1808, 30-12-1808, 31-12$1808,1-1-1809$ y $2-1-1809$.

84 Gazeta de Madrid, 4-1-1809, 6-1-1809 y 7-1-1809.

85 Gazeta de Madrid, 29-3-1808. 
que la gestión de los Bonaparte era inmejorable y que la presencia de la dinastía era sinónimo de prosperidad y felicidad, ya fuese en Francia, en Nápoles o en España.

La Gazeta de Madrid se adelantó unos meses a las innovaciones del gobierno y las ensalzó antes de que fueran aplicadas en España, no obstante, una vez planeadas aquí, alabó las reformas españolas y ya no tuvieron que recurrir a los ejemplos de Nápoles y Francia. El 9 de noviembre de 1809, apenas dos semanas después del anuncio el 26 de octubre de la fundación de un colegio en cada capital, el periódico publicó el primero de cinco artículos a favor del sistema educativo josefino. Los redactores defendían la importancia de que el nuevo método de enseñanza fuese general y la educación pública. La Gazeta de Madrid subrayaba las ventajas de la instrucción de los más jóvenes, al tiempo que criticó a las autoridades españolas por el abandono histórico de la cultura: "la instrucción pública [estaba] en la mayor barbarie: la educación del pueblo abandonada [...]" ${ }^{\prime 86}$. De nuevo, la gestión de la casa Borbón era objeto de crítica. Los josefinos les reprochaban que hubiesen construido tantos templos y tan pocas escuelas. La incorporación de las niñas a la enseñanza pública fue otro reclamo utilizado por la propaganda para demostrar los deseos regeneradores de José. El 2 de junio de 1812 la Gazeta de Madrid publicó un artículo dirigido a las mujeres en el que su autor, que firmaba con el seudónimo de Prudencia Paz, denunciaba por una parte el olvido de los gobiernos anteriores por la educación femenina y, por otra intentaba convencer a las mujeres de que José acabaría con esa política discriminatoria ${ }^{87}$. La propaganda integró los asuntos femeninos en su discurso para que las mujeres fueran conscientes de que el monarca las tenía presentes en su política reformista ${ }^{88}$.

Las mejoras económicas también tuvieron una difusión notable en la prensa los años de la guerra. El entorno de José recurrió a su política económica para demostrar su espíritu modernizador, pero con este fin tampoco dudó en reprobar la gestión de los viejos reyes. De todos los decretos económicos publicados en 1809, el que más páginas ocupó en la Gazeta de Madrid fue el del pago de la deuda pública ${ }^{89}$. El 13 de junio de ese año, apenas cuatro días después de su aprobación, los josefinos publicaron el primero de una serie de artículos en los que se defendía su aplicación inmediata. Entonces también anunciaron que la llegada de José a España acabaría con la corruptela de la casa Borbón. Al día siguiente el periódico divulgó otro texto similar titulado "Reflexiones sobre el decreto de S. M. del 9 de este mes para la extinción de la deuda pública" que, por su extensión, fue publicado en diez números ${ }^{90}$. Los josefinos primero enumeraron los beneficios del pago de la deuda, y luego, como tenían por costumbre, atizaron a los Borbones comparando su gestión con la de la nueva dinastía. Como ocurriese en el verano de 1808, la prensa recurre a la gestión de la monarquía saliente para recalcar las ventajas de la nueva ${ }^{91}$ :

86 El Imparcial, 9-6-1809.

87 Gazeta de Madrid, 2-6-1812.

88 Gazeta de Madrid, 21-2-1810.

89 Véase igualmente El Imparcial, 18-7-1809.

90 Gazeta de Madrid, 14-6-1809, 15-6-1809, 16-6-1809, 17-6-1809, 18-6-1809, 19-6-1809, 20-6-1809, 21-6-1809, 22-6-1809 y 23-6-1809. El Imparcial también publicó noticias que ahondaban en la imagen de José I como salvador de la economía. El Imparcial, 30-5-1809, 9-6-1809 y 16-6-1809.

91 Véase la crítica que hace el general O'Farrill de los Borbones en: Gazeta de Madrid, 31-1-1810. 
Sí españoles; a los gobiernos de obscuridad, de tinieblas, de destrucción y de mala fe, que nos habían puesto al borde del precipicio, ha sucedido un gobierno de claridad, de luces, de economía, de lealtad y reparador. Nuestro Soberano conoce nuestras necesidades, y quiere remediarlas; conoce la causa de las calamidades de la nación, y los medios más a propósito de repararlas: sabe que el crédito público es el apoyo más firme de un estado y que por haberse perdido entre nosotros ha sido consiguiente la ruina de innumerables familias y la decadencia del comercio, de la industria, de la agricultura $^{92}$.

La propaganda ensalza la política económica de José antes de su puesta en marcha en España, y lo mismo ocurre con la crítica a los Borbones. Así era como se pretendía abonar el terreno para que el proyecto regenerador tuviese mejor acogida entre los españoles. Los primeros artículos a favor del plan económico fueron publicados en enero de 1809. El 26 de febrero la Gazeta de Madrid denunció la mala situación económica de la monarquía en el artículo "Economía política":

La agricultura decayendo; las fábricas arruinadas; la industria paralizada; el comercio interior encadenado por las leyes mismas, que debieran protegerlo y fomentarlo, y el exterior detenido por el sistema actual de nuestras aduanas, y por la tiranía de los ingleses [...] una deuda inmensa que ha arruinado el crédito público, y que ocasiona al vasallo penosos sacrificios para su extinción: las casas principales de comercio de España arruinadas o extenuadas por las necesidades del erario; y por último una guerra interior, que arruina nuestros pueblos, aparta el labrador del arado y al artesano de su taller, y de este modo va agotando los recursos del estado; he aquí el cuadro que presenta España en esta época, y hacia donde debe dirigir el gobierno sus providencias para sacarla de tan infeliz situación ${ }^{93}$.

El periódico oficial recordaba la posición privilegiada de la economía, pero señalaba que la prosperidad era cosa ya del pasado. La economía estaba enferma y necesitaba remedios urgentes. El inventario de las trabas no era reducido. En la esfera agraria uno de los problemas era el sistema de la propiedad. La abundancia de tierras baldías y vinculadas fue otro, pues la baja productividad provocaba que las capitales quedasen desprovistas de los alimentos de primera necesidad ${ }^{94}$. Unos años antes España abastecía a otros reinos, pero ahora carecía de muchos productos y dependía del extranjero. El panorama industrial y comercial tampoco era mejor. La inexactitud de las leyes, el sistema de las rentas o la estricta reglamentación de los gremios eran algunos de los problemas que habían provocado la ruina de ambos sectores. En los primeros artículos la Gazeta de Madrid explicaba los problemas económicos de la monarquía, y en los dos siguientes exponía las reformas aplicables ${ }^{95}$. El periódico hablaba del nuevo gobierno como la única alternativa que podía remediar la crisis.

92 Gazeta de Madrid, 14-6-1809.

93 Gazeta de Madrid, 27-2-1809. Este artículo fue publicado los días 26 y 27 de febrero, y 1 y 3 de marzo de 1809 .

94 En defensa de la desvinculación de las tierras promovida por José véanse: Gazeta de Madrid, 30-61809, 1-7-1809, 2-7-1809, 5-7-1809, 6-7-1809, 7-7-1809 y 8-7-1809.

95 En la mayor parte de los casos las medidas que se plantearon en estos artículos fueron puestas en marcha pocos meses después por el gobierno. Gazeta de Madrid, 1-3-1809. 
Solo el monarca y su política regeneradora conseguirían encumbrar a la monarquía al estado de bienestar disfrutados antes ${ }^{96}$. El periódico reconocía que el reto era grandioso, pero animaba a los españoles a que confiasen en la gestión de José. El florecimiento de la agricultura, la industria, el comercio, etc. estaba sujeto a la puesta en marcha del proyecto regenerador ${ }^{97}$. Todo esto, sin embargo, a principios de 1809 era un espejismo difícil de entender para los españoles, que veían en la nueva dinastía el origen de todos sus males. Por eso la propaganda recurre de nuevo al reinado napolitano. Para demostrar el espíritu regenerador de José su entorno publicó en la Gazeta de Madrid algunas notas sobre los progresos económicos de Nápoles durante su reinado. En febrero de 1809 el medio anunció que en menos de tres años el soberano, además de extinguir una deuda de 85 millones, había duplicado las rentas de 119 a 204 millones $^{98}$. Este mismo objetivo hizo que el periódico mencionase los progresos educativos, científicos, urbanísticos, etc. de los Bonaparte en Nápoles y Francia ${ }^{99}$.

El afán de la prensa por presentar a José ante la opinión pública como un rey regenerador hizo que sus redactores escribieran decenas de páginas a favor de su proyecto modernizador. Dada la guerra de propaganda abierta, los josefinos incorporaron la política regeneradora en su campaña para favorecer la imagen de José, pero las reformas no fueron ideadas para cumplir esa función. Pese a ello, en la época afloraron voces que negaron el componente regenerador de algunas medidas. Por ejemplo, la de la ampliación del Jardín Botánico de Madrid. El embajador La Forest anuló el componente científico del proyecto y subrayó que el decreto obedecía a intereses políticos. La Forest advirtió que José solo pretendía mostrar las buenas intenciones de su gobierno después de los encarcelamientos y las deportaciones producidas con motivo de su retorno a Madrid en diciembre de 1808: “Je crois qu'il n'est présenté au public dans les circonstances actuelles, qu'à cause des considérations qui lui servent de préambule. Il est bien, sans doute, que des actes paternels soient mêlés aux actes du sévérité que le Roi a été conduit irrésistiblement à exercer" ${ }^{100}$. El diplomático plantea que la ampliación del Jardín Botánico se hace por conveniencia de imagen más que por utilidad científica. Sin embargo, ambos intereses no son contradictorios. El ensalzamiento de la imagen pública de José a través de la política regeneradora no niega su compromiso científico. El uso promocional de las reformas no implica que estas fueran proyectadas solo para enaltecer el perfil del monarca. El plan de mejoras tuvo una dosis de publicidad innegable. Pero la dinamización de la economía, el avance de la cultura y la ciencia, la reordenación urbanística, etc. respondían al deseo personal de José de encumbrar a la nación a una posición privilegiada. El rey percibía la ciencia como conocimiento útil y la desarrolló en sus diferentes esferas por

96 Gazeta de Madrid, 3-3-1809.

97 La Gazeta de Madrid publicó otros artículos referentes a la situación existente antes de la llegada de José y a los avances de su gestión: Gazeta de Madrid 23-5-1809, 24-5-1809, 25-5-1809, 26-5-1809 y 29-61809 .

98 Gazeta de Madrid, 21-2-1809. La fundación de escuelas y seminarios para la educación pública, la abolición del feudalismo, la independencia del poder judicial, la reorganización del ejército o la explotación de las tierras de manos muertas fueron otros de los avances.

99 Gazeta de Madrid, 29-12-1808, 30-12-1808, 31-12-1808, 1-1-1809, 2-1-1809 y 9-1-1809.

100 La Forest (ed. de G. de Grandmaison): Correspondance du comte de La Forest, ambassadeur de France en Espagne, 1808-1813, París, Société d'Histoire contemporaine, 1905, vol. II, p. 84. 
sus ventajosos resultados. José intentó renovar la nación para favorecer su progreso y el de los españoles, convirtiéndose la mejora de su perfil público en un estímulo secundario. El pensamiento ilustrado del soberano fue el impulso que inauguró la regeneración en España.

Los josefinos enfrentaron las ventajas y los defectos de ambas dinastías, monarcas incluidos, para demostrar la superioridad de la opción napoleónica. Sin embargo, los patriotas no tardaron en hacer una lectura distinta. En realidad, ambos bandos hicieron uso de la misma estrategia para deslegitimar a su oponente. Así que como hicieran los Bonaparte con la casa Borbón, la propaganda fernandina asoció a Napoleón y a José con la destrucción, el mal, la miseria, etc. Para ellos la llegada de José no representaba la salvación de la monarquía, ni el progreso de la nación ni, menos, el inicio de una etapa regeneradora. El mito del monarca salvador lo encarna ahora Fernando VII en confrontación a José, causante, junto a su hermano, de todos los males de la monarquía. Los medios fernandinos perseguían un doble objetivo: por un lado la defensa de la independencia nacional frente al intrusismo galo y, en consecuencia, el ensalzamiento de la España de los Borbones y, por otro, el inicio de una campaña de desprestigio contra Napoleón, su imperio y José I. El descrédito del plan regenerador se enmarca dentro de este segundo objetivo. La crítica contra la política modernizadora fue menor, sobre todo si se compara con otras esferas, pero la cuestión no pasó desapercibida. Napoleón y su imperio, presentados por la propaganda josefina como paradigma de regeneración, tardaron poco en recibir las primeras críticas. La opulenta y radiante Francia de la que hablaba Napoleón en sus periódicos fue neutralizada por la propaganda enemiga. El autor del Prospecto a la obra titulada: El Observador Político y Militar de España afirmó que la experiencia francesa debía evitarse en España por todos los medios porque el imperio, "lejos de avanzar hacia la regeneración social, retrocedió con espanto hasta los siglos bárbaros"101. El imperio no debía ser venerado ni envidiado por los españoles, todo lo contrario:

La Francia en un espacio de menos de veinte años ofrece el espectáculo más extraordinario y más digno de compasión, de que hay ejemplo en las historias; un Gobierno debilitado por envejecidos abusos llama en su socorro a la nación [...] ¡Quién será capaz de describir el estado de la Francia en esta época de anarquía! Casi toda su nobleza asesinada, la restante prófuga, la Religión escarnecida y abandonada, los Ciudadanos virtuosos temblando en el retiro $[\ldots]^{102}$.

Los patriotas denunciaron que la política económica de Napoleón había llevado a Francia a la ruina. Pero también responsabilizaron al corso de la decadencia del resto de los países que integraban su imperio ${ }^{103}$. En aras de minar su plan regenerador, tampoco dudaron en comparar la decadencia de esas naciones (Holanda, Dinamarca, etc.) con los progresos económicos de Inglaterra, aliada principal de los Borbones:

101 Prospecto a la obra titulada: El Observador Político y Militar de España, $\mathrm{n}^{\mathrm{o}} 1$.

102 ¿Cuál será el fruto de la revolución francesa? La esclavitud de la Francia y la restauración de España, Valencia, por Joseph de Orga, 1808. Véanse igualmente: Correo de Valencia, 11-4-1811, Semanario Patriótico, 6-10-1808 y Correo de Valencia, 4-7-1811.

103 Correo de Valencia, 10-1-1811, Gazeta Ministerial de Sevilla, nº 48, noviembre de 1808. 
Mientras Bonaparte devasta las Potencias más comerciantes agregándolas a su grande Imperio, la Inglaterra adquiere las pocas colonias que quedaban a la Francia en las Indias orientales y occidentales [...] mientras Bonaparte envilece a todos los débiles Potentados del continente, la Inglaterra recibe con hospitalidad inapreciable a los nobles Monarcas que no han querido subscribir al oprobio: y en fin mientras Bonaparte anuncia su desembarco en Inglaterra, esta envía tropas a Indias, a Portugal, a España y Sicilia. ¡Qué diferencia de Naciones! ¡Qué diferencia de poder! 104

Los fernandinos, después de desmitificar la imagen del imperio, demonizaron el espíritu regenerador del emperador. Napoleón, antaño héroe nacional, fue presentado como un ser despreciable enviado a Europa para destruir la humanidad. Él ya no representaba la regeneración ni el progreso de la nación, sino su destrucción, y José I lo mismo. La imagen de salvador de Napoleón fue combatida relacionando su presencia en España y en muchos otros países a numerosas adversidades. La hipocresía, la ambición y su carácter miserable, traicionero, criminal y mentiroso fueron algunos de los sambenitos atribuidos a Napoleón. Pero por encima de ello se recalcó sus planes destructores y la ilegitimidad con la que había fundado su imperio. Europa había sido arrasada, y de no remediarlo España seguiría el mismo destino con José I a la cabeza. La prensa negó la política conciliadora de los Bonaparte y asoció su presencia con la ruina económica y la infelicidad del pueblo. De los papeles patrióticos se desprendía que la opción josefina era sinónimo de degeneración, en ningún caso de innovación. Los fernandinos viciaron todos los "testimonios" que, según los josefinos, demostraban el carácter regenerador de su dinastía, incluidos la Constitución de Bayona y el reinado napolitano de José ${ }^{105}$. Los folletos El tío Lagarto y su proclama a los chisperos de Madrid, ¿Napoleón ha regenerado a España? y el Despertador cristiano político... dan cuenta de ello ${ }^{106}$. En El tío Lagarto... los patriotas desprestigian los propósitos regeneradores de Napoleón inspirándose en su proclama de 25 de mayo de 1808:

\author{
Mi misión se dirige a renovarla. \\ Trágate esa, y si no, envocate en pinto \\ con todo lo demás, mientras yo corro \\ a este Renovaor de los abismos. \\ Mejoraré vuestras estituciones... \\ ¿Mejoraré quien siempre malo ha sio? \\ ¿Y a una Nación, que si algo tié de mala, \\ Es no haberle sacao el entresijo? \\ ¡Jueran famosas sus estituciones!
}

104 Correo de Valencia, 11-4-1811.

105 Gazeta de Valencia, 7-3-1809 y 21-3-1809, Diario de Valencia, 6-6-1808 y 8-8-1808, Semanario Patriótico, 6-10-1808, P. D. D. R. N., Los votos de un español o cartas sobre la situación actual de España, las causas de sus males y los medios más oportunos de remediarlos y precaverlos en los sucesivo, Madrid, Impr. de Collado, 1808.

106 El tío Lagarto y su proclama a los chisperos de Madrid, Valencia [?], 1808, ¿Napoleón ha regenerado a España?, López, Simón: Despertador cristiano politico. Se manifiesta que los autores del trastorno universal de la Iglesia y de la Monarquía son los filósofos Franc-masones: se descubren las artes diabólicas de que se valen y se apuntan los medios para atajar sus progresos, Valencia, Impr. de Salvador Faulí, 1809. 


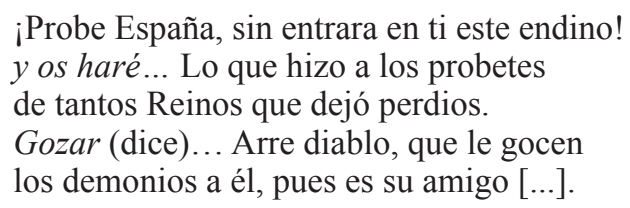

En el papel ¿Napoleón ha regenerado a España?, su autor, también anónimo, denuncia que Napoleón deseaba regenerar España siguiendo los mismos patrones aplicados en Francia e Italia, esto es, aniquilando la agricultura, el comercio, la industria y las artes. Simón López, autor del Despertador cristiano político... hace hincapié igualmente en los efectos negativos de la regeneración del imperio:

Ha sido necesario arruinar todos los Gobiernos y Soberanos de Italia y Alemania, robar todos los Estados de la Iglesia Romana [...] Secularizar, profanar obispados y Abadías sin número; extinguir todos los Monasterios y establecimientos piadosos, cabildos, confraternidades: esclavizar, saquear, tiranizar muchísimas ciudades anseáticas o republicanas, Principados y Señoríos antiquísimos. Finalmente, hacer innumerables pobres, mendigos, huérfanos, viudas, muertos, heridos y estropeados; cautivos, presos, desterrados, esclavizados. Estos son los cimientos de la grandeza, nobleza y opulencia de Napoleón y de sus hermanos, cuñados ahijados, colegas y camaradas. Así los FrancMasones con su hermano terrible, Napoleón, han regenerado la Europa y presumen regenerar las Españas, las Américas y todo el mundo, si Dios y vosotros, Españoles, no les atajarais los pasos.

Simón López, obispo y antes diputado servil en Cádiz, no asocia la regeneración de la nación con la política de beneficencia, ni con las mejoras científicas, económicas, urbanísticas, etc., sino con la extinción de la religión católica: "Precaución contra la cabala de los malos y coligación de los impíos Franc-Masones, sofistas incrédulos que tienen jurado el regenerar el mundo, esto es, aniquilar la religión revelada, y plantar en todas partes la religión natural, o el materialismo y ateísmo, que es su decantada regeneración".

Los patriotas demonizaron el título de rey regenerador, pero también desprestigiaron las medidas reformadoras, sobre todo las que más podían beneficiar la imagen pública del monarca. Los motes peyorativos de "rey plazuelas", "Pepe Baraja", o el enfoque negativo de la expresión "rey filósofo" fueron una derivación negativa de la política regeneradora aplicada en España. A José Bonaparte le sirvió de poco las reformas que llevó a cabo y la puesta en circulación de sus planes regeneradores. $\mathrm{Su}$ imagen pública no mejoró y tampoco logró captar la opinión de los españoles. De haber sido un Borbón el responsable de las reformas probablemente habría pasado a la historia con el sobrenombre de "rey reformador", pero José, por su condición de intruso, no lo mereció. 